Article

\title{
Design of a Four-Branch $L C L$-Type Grid-Connecting Interface for a Three-Phase, Four-Leg Active Power Filter
}

\author{
Wu Cao *, Kangli Liu, Yongchao Ji, Yigang Wang and Jianfeng Zhao \\ School of Electrical Engineering, Southeast University, No 2 Si Pai Lou, Nanjing 210096, China; \\ E-Mails: kangcumt@yeah.net (K.L.); song871001@126.com (Y.J.); songj@nrec.com (Y.W.); \\ jianfeng_zhao@seu.edu.cn (J.Z.) \\ * Author to whom correspondence should be addressed; E-Mail: 13813017660@163.com; \\ Tel.: +86-138-1301-7660.
}

Academic Editor: Frede Blaabjerg

Received: 6 January 2015 / Accepted: 16 February 2015 / Published: 27 February 2015

\begin{abstract}
Compared with the three-phase, two-split-capacitor active power filter (3P2C-APF), the three-phase, four-leg active power filter (3P4L-APF) has been widely used in three-phase, four-wire grid utility for power quality control due to its numerous advantages, such as higher current output capability, particularly in phase $\mathrm{N}$, lower current and easier voltage control on the DC-side. However, designing the grid-connecting interface, which is between the voltage source converter (VSC) and grid utility, is rather difficult due to the higher requirement for current ripple filtering in phase $\mathrm{N}$, cross-coupling in four phases and lack of relevant design methodology and specification. In this paper, a four-branch LCL-type (4B-LCL) grid-connecting interface is proposed for 3P4L-APF, which features better current ripple filtering performance without decreasing the current output capability in all phases. First, this paper describes the mathematical models of 4B-LCL in the fully-complex-vector form from the zero and non-zero sequence perspective, resulting in two independent and uniform equivalent circuits without cross coupling terms. Then, the $4 B-L C L$ parameter design method based on the most comprehensive performance index is proposed, including three main stages as the specification: performance index requirement determination, fulfillment of that requirement, and verification. Finally, the validity and effectiveness of the proposed design are proven by the simulated and experimental results of a 3P4L-APF with $4 B-L C L$.
\end{abstract}


Keywords: three-phase four-leg (3P4L); four-branch $L C L$ (4B-LCL); grid-connecting; active power filter (APF); power quality (PQ); pulse-width-modulated (PWM) converter

\section{Introduction}

Active power filters (APFs) can be classified into two types according to their grid connection mode: three-phase three-wire $(3 \mathrm{P} 3 \mathrm{~W})$ and three-phase four-wire $(3 \mathrm{P} 4 \mathrm{~W})$. The former can only control power quality problems in phase $\mathrm{A}, \mathrm{B}$, and $\mathrm{C}$, whereas the latter can also in phase $\mathrm{N}$. Because the low-voltage distribution system is commonly a 3P4W power system along with numerous unbalanced or single-phase harmonic loads, the 3P4W-APF has been more widely utilized in practical applications [1-6].

The power circuit of an APF consists of two main parts: a voltage source converter (VSC) and a grid-connecting interface. According to the structure of the VSC, the 3P4W-APF can be further classified into two types [5,6]: the three-phase, two-split-capacitor type (3P2C) and the three-phase, four-leg type (3P4L), as shown in Figure 1. Compared with the 3P2C-APF, the 3P4L-APF has two key advantages simply at the expense of an additional IGBT in phase N, which include (1) larger current output capacity for its more adequate DC voltage utilization and (2) easy DC-side design and voltage control for its low DC-side current and no need for voltage balancing, such as in the $3 \mathrm{P} 2 \mathrm{C}$. Thus, the 3P4L-APF is more suitable for medium and high-power applications [6]. However, its grid-connecting interface, which connects the VSC and grid utility, is difficult to design because of its higher requirement of current ripple filtering in phase $\mathrm{N}$, cross-coupling in four phases and lack of relevant design methodology and specification. In [5,7-9], the authors conducted various research studies on the three-phase, four-branch APF structure but did not provide an analysis of the above-mentioned issue. Specifically, Sami Pettersson et al. adopted the $L C L$ interface for phase ABC and the $L$ interface for phase $\mathrm{N}$ in [5], showing a relatively good filtering effect. However, that study did not provide detailed design steps of decoupling or $L C L$ parameters.

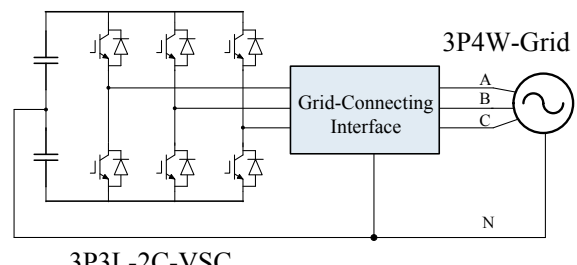

(a) Three-Phase Two-Split-Capacitor

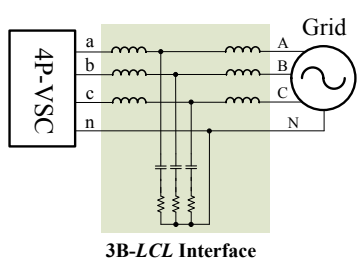

(c) Three-Branch $L C L$-Type Interface

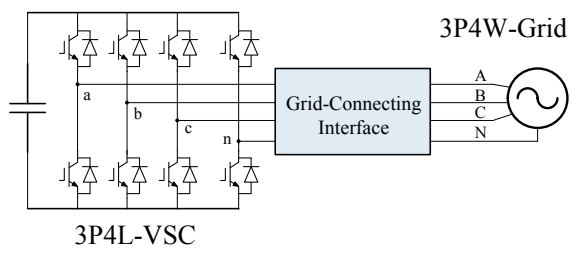

(b) Three-Phase Four-Leg

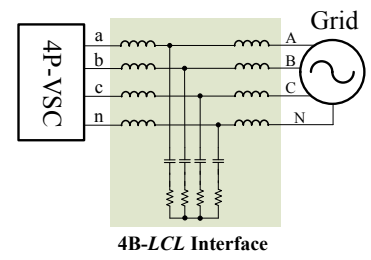

(d) Four-Branch $L C L$-Type Interface

Figure 1. Three-phase, four-wire active power filter and its grid-connecting interface. 
There are two common types of grid-connecting interfaces: $L$-type and $L C L$-type [5,10-17], whose functions can be summarized as two aspects: (1) transforming the voltage output from VSC into controllable current injected to the grid with little power loss and (2) filtering out the switching frequency harmonic current from the grid-injecting current, which is caused by the PWM-voltage output of the VSC $[18,19]$. Compared with the $L$-type grid-connecting interface, the $L C L$-type receives more utilization because it offers better harmonic attenuation and efficiency at a smaller size. The research on current control and design of the $L C L$-type grid-connecting interface in single-phase or three-phase, three-wire applications has been conducted in [20-25]. However, there is little information available describing the systematic design of the $L C L$-type grid-connecting interface for the three-phase, four-wire application, especially for the grid connection of the 3P4L-APF.

In this paper, a four-branch $L C L$-type $(4 B-L C L)$ grid-connecting interface and detailed parameter design steps are proposed for 3P4L-APF based on mathematical model analysis for decoupling and the most comprehensive performance indexes. Firstly, for removing coupling between each phase, the analysis is processed from the perspective of non-zero-sequence and zero-sequence, respectively. Then, the most comprehensive performance indexes from the designed $L C L$ circuit parameters will be obtained in the impedance perspective. Finally, the $4 B-L C L$ parameter design method based on the most comprehensive performance index is proposed, including three main stages: (1) performance requirements determination; (2) fulfilling the performance requirements and (3) performance requirements verification. The validity and effectiveness of the proposed design are proved by the simulated and experimental results of a $3 \mathrm{P} 4 \mathrm{~L}-\mathrm{APF}$ with $4 B-L C L$.

\section{System Description and Modeling}

\subsection{Topology Description}

As illustrated in Figure 2, the proposed four-branch $L C L$-type interface connects the $3 P 4 L$-VSC to the grid utility. $L_{l a b c}$ and $L_{2 a b c}$, denote the converter-side and grid-side $L-R$ plant, respectively, in phases $\mathrm{A}, \mathrm{B}$, and $\mathrm{C} . H F_{a b c}$ denotes the filter-side $R-C$ plant. $L_{1 n}, L_{2 n}$ and $H F_{n}$ denote the corresponding elements in phase $\mathrm{N}$.

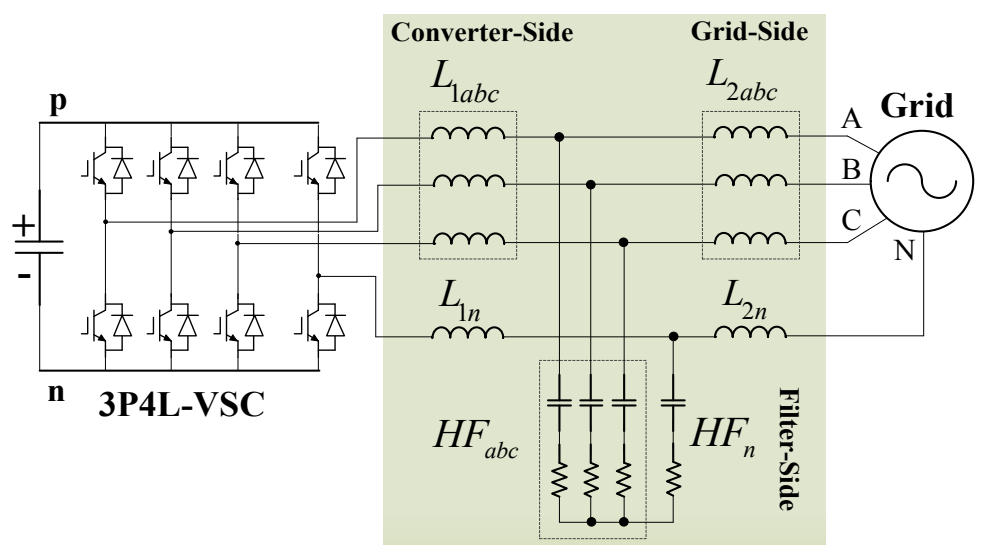

Four-Branch $L C L$-Type Interface

Figure 2. $3 P 4 L-A P F$ with the proposed $4 B-L C L$ interface. 
The functions of the grid-connecting interface can be summarized into two aspects: (1) transforming the VSC output voltage into controllable current injected to the grid with little power loss, and (2) filtering out the so-called current ripple, which is harmonic current around the integral multiples of the switching frequency and is only caused by the PWM-voltage output of 3P4L-VSC.

Compared with the traditional $3 B-L C L$ interface, the proposed topology adopts an additional $L C L$ branch for phase $\mathrm{N}$, which causes a more satisfactory attenuation effect of current ripple and the decoupling for parameter design in phases A, B, C and N. The related details will be provided below.

\subsection{Topology Analysis}

Figure 3 illustrates the equivalent circuit for topology analysis. Four controlled voltage sources have replaced the four legs of VSC. The analysis of the circuit will be processed in the $s$ domain from two perspectives.

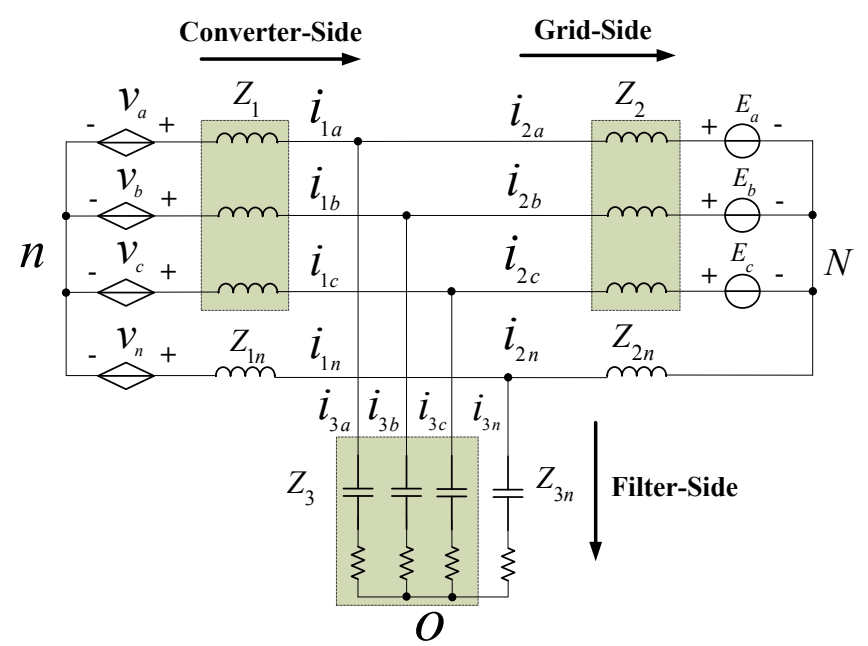

Figure 3. Equivalent circuit.

$Z_{1}$ and $Z_{2}$ denote the converter-side and grid-side branch impedance, respectively, in phases A, B, and C. $Z_{1 n}$ and $Z_{2 n}$ denote the converter-side and grid-side branch impedance, respectively, in phase $\mathrm{N}$. $Z_{3}$ and $Z_{3 n}$ denote the filter-side branch impedance in phases $\mathrm{A}, \mathrm{B}, \mathrm{C}$ and phase $\mathrm{N}$, respectively.

\subsubsection{Analysis in the Per-Phase Perspectives}

When the voltages between $n O$ and $N O$ are replaced by the voltage sources $U_{n O}$ and $U_{N O}$, the equivalent circuit in Figure 3 can be divided into four groups in unified form, as shown in Figure 4.

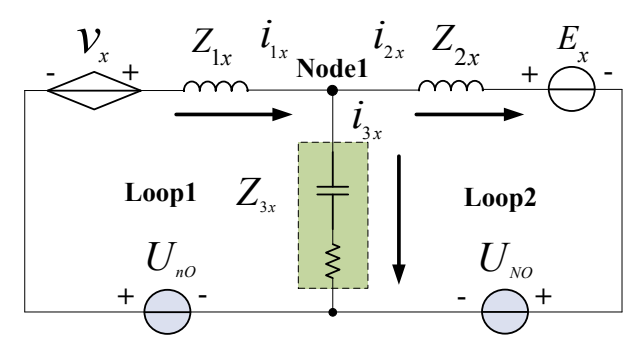

Figure 4. Equivalent circuit in each phase $(x=A, B, C, N)$. 
According to the basis theory of circuits, four groups of Equations (1)-(4), can be deduced from Figure 4.

Deduced from Loop 1:

$$
\left[\begin{array}{l}
I_{1 a}(s) Z_{1 a}(s) \\
I_{1 b}(s) Z_{1 b}(s) \\
I_{1 c}(s) Z_{1 c}(s) \\
I_{1 n}(s) Z_{1 n}(s)
\end{array}\right]+\left[\begin{array}{c}
I_{3 a}(s) Z_{3 a}(s) \\
I_{3 b}(s) Z_{3 b}(s) \\
I_{3 c}(s) Z_{3 c}(s) \\
I_{3 n}(s) Z_{3 n}(s)
\end{array}\right]=\left[\begin{array}{c}
V_{a}(s) \\
V_{b}(s) \\
V_{c}(s) \\
V_{n}(s)
\end{array}\right]+\left[\begin{array}{c}
U_{n O}(s) \\
U_{n O}(s) \\
U_{n O}(s) \\
U_{n O}(s)
\end{array}\right]
$$

Deduced from Loop 2:

$$
-\left[\begin{array}{l}
I_{2 a}(s) Z_{2 a}(s) \\
I_{2 b}(s) Z_{2 b}(s) \\
I_{2 c}(s) Z_{2 c}(s) \\
I_{2 n}(s) Z_{2 n}(s)
\end{array}\right]+\left[\begin{array}{c}
I_{3 a}(s) Z_{3 a}(s) \\
I_{3 b}(s) Z_{3 b}(s) \\
I_{3 c}(s) Z_{3 c}(s) \\
I_{3 n}(s) Z_{3 n}(s)
\end{array}\right]=\left[\begin{array}{c}
E_{a}(s) \\
E_{b}(s) \\
E_{c}(s) \\
E_{n}(s)
\end{array}\right]+\left[\begin{array}{c}
U_{N O}(s) \\
U_{N O}(s) \\
U_{N O}(s) \\
U_{N O}(s)
\end{array}\right]
$$

Deduced from Node 1:

$$
\left[\begin{array}{c}
I_{2 a}(s) \\
I_{2 b}(s) \\
I_{2 c}(s) \\
I_{2 n}(s)
\end{array}\right]=\left[\begin{array}{c}
I_{1 a}(s) \\
I_{1 b}(s) \\
I_{1 c}(s) \\
I_{1 n}(s)
\end{array}\right]-\left[\begin{array}{c}
I_{3 a}(s) \\
I_{3 b}(s) \\
I_{3 c}(s) \\
I_{3 n}(s)
\end{array}\right]
$$

Deduced from Nodes n, o, and N:

$$
\left[\begin{array}{c}
I_{1 a}(s) \\
I_{2 a}(s) \\
I_{3 a}(s)
\end{array}\right]+\left[\begin{array}{c}
I_{1 b}(s) \\
I_{2 b}(s) \\
I_{3 b}(s)
\end{array}\right]+\left[\begin{array}{c}
I_{1 c}(s) \\
I_{2 c}(s) \\
I_{3 c}(s)
\end{array}\right]=-\left[\begin{array}{c}
I_{1 n}(s) \\
I_{2 n}(s) \\
I_{3 n}(s)
\end{array}\right]
$$

Equations (1) and (2) illustrate that $U_{n O}$ and $U_{N O}$ cause coupling between each phase. Thus, the equivalent circuit in Figure 4 is not suitable for the design of $L C L$ parameters and grid-injecting current control.

\subsubsection{Analysis in the Non-Zero-Sequence and Zero-Sequence Perspectives}

To remove $U_{n O}$ and $U_{N O}$ for decoupling, the analysis is processed from the perspectives of non-zero-sequence and zero-sequence, respectively.

The complex vector s-transfer function in Equation (5) for describing the non-zero-sequence circuit can be obtained by conducting symmetrical parameter design in phase $A B C$ and substituting the Clarke transformation matrix 2/3 $\left[1, \mathrm{e}^{\mathrm{j} 2 \pi / 3}, \mathrm{e}^{-\mathrm{j} 2 \pi / 3}\right]$ into both sides of Equations (1)-(3).

$$
\left\{\begin{array}{l}
I_{1}(s) Z_{1}(s)+I_{3}(s) Z_{3}(s)=V(s) \\
-I_{2}(s) Z_{2}(s)+I_{3}(s) Z_{3}(s)=E(s) \\
I_{2}(s)=I_{1}(s)-I_{3}(s)
\end{array}\right.
$$


where

$$
\begin{aligned}
& Z_{1}(s)=Z_{1 a}(s)=Z_{1 b}(s)=Z_{1 c}(s) \\
& Z_{2}(s)=Z_{2 a}(s)=Z_{2 b}(s)=Z_{2 c}(s) \\
& Z_{3}(s)=Z_{3 a}(s)=Z_{3 b}(s)=Z_{3 c}(s)
\end{aligned}
$$

From Equations (1)-(4), the real s-transfer function for the zero-sequence circuit can be obtained as shown in Equation (6).

$$
\left\{\begin{array}{l}
I_{1 n}(s) Z_{1 n \_e q}(s)+I_{3 n}(s) Z_{3 n \_e q}(s)=V_{n \_e q}(s) \\
-I_{2 n}(s) Z_{2 n \_e q}(s)+I_{3 n}(s) Z_{3 n \_e q}(s)=-E_{0}(s) \\
I_{2 n}(s)=I_{1 n}(s)-I_{3 n}(s)
\end{array}\right.
$$

where

$$
\begin{aligned}
& V_{n \_ \text {eq }}(\mathrm{s})=V_{n}(\mathrm{~s})-V_{0}(\mathrm{~s}) \\
& Z_{x n \_e q}(\mathrm{~s})=Z_{x}(\mathrm{~s}) / 3+Z_{x n}(\mathrm{~s}) \quad(x=1,2,3)
\end{aligned}
$$

From Equations (5) and (6), two independent equivalent circuits have been obtained, as illustrated in Figure 5. $U_{n O}$ and $U_{N O}$ have disappeared, which brings the decoupling of each phase. In addition, the left of Figure $5 \mathrm{~b}$ shows that the additional $L C L$ branch for phase $\mathrm{N}$ brings the design of the zero-sequence circuit independent from the non-zero-sequence. Thus, the design of the 4-branch $L C L$ parameter and 4-phase grid-injecting current control becomes the design simply for two independent equivalent circuits in the non-zero-sequence and zero-sequence.

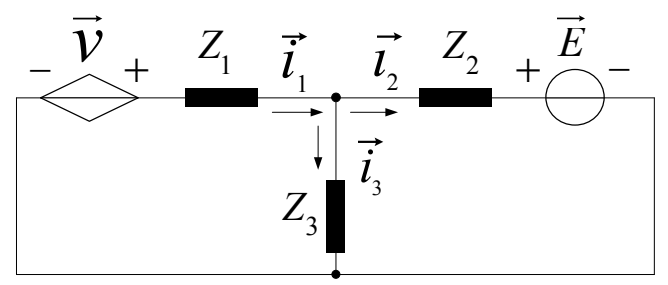

(a)
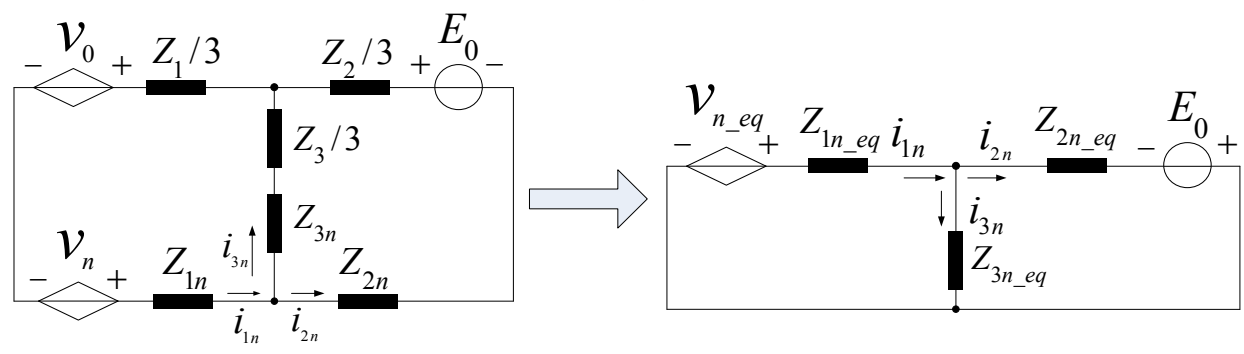

(b)

Figure 5. Equivalent circuit in (a) the non-zero-sequence and (b) zero-sequence.

\subsection{Model for Parameter Design}

Figure 6 illustrates two s-transfer function blocks deduced from the two independent equivalent circuits in Figure 5. When the real signal in the zero-sequence block was regarded as a special complex 
signal whose imaginary part always equals zero, the two blocks can be entirely in the same style with the unified complex vector form. Furthermore, the s-transfer function matrix can be obtained for the analysis of the characteristic of the $L C L$ circuit, which will be shown in next section.

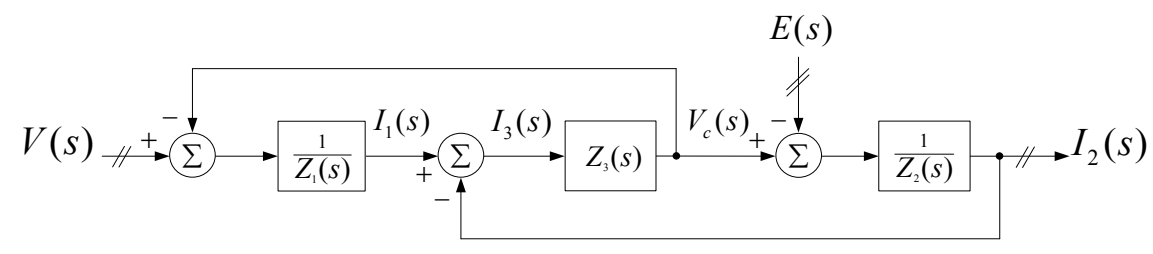

(a)

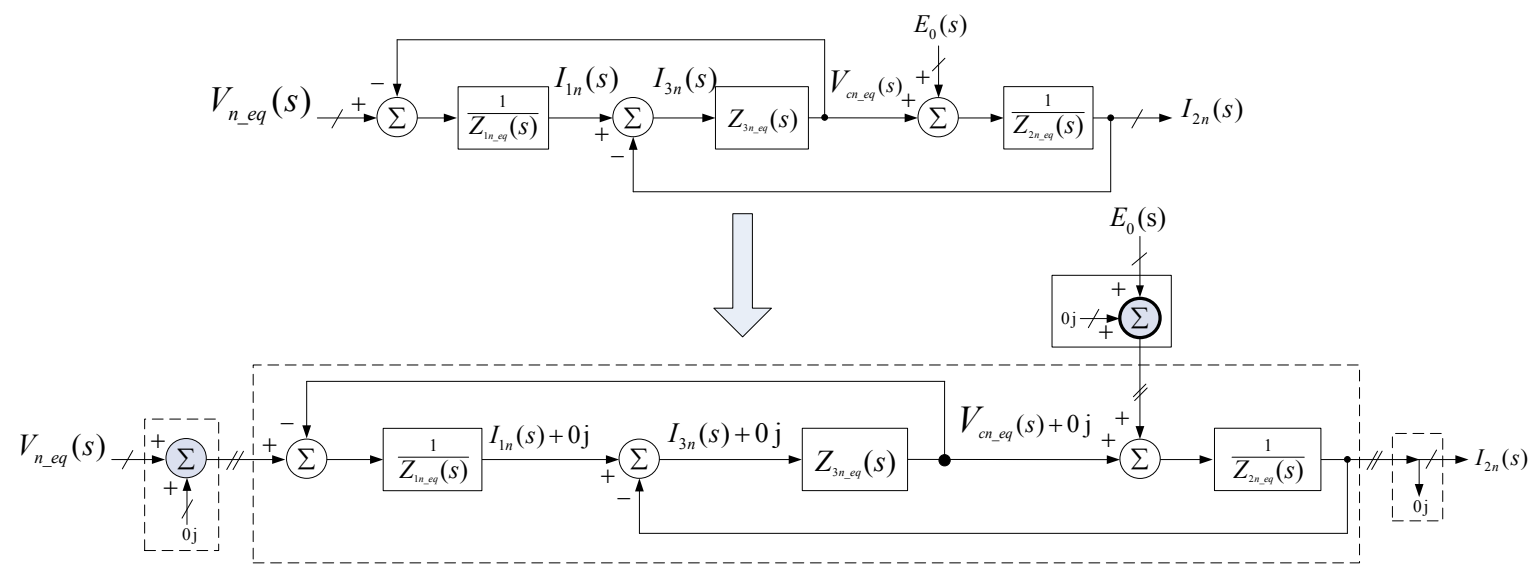

(b)

Figure 6. 4B- $L C L$ model in the (a) non-zero-sequence and (b) zero-sequence.

\section{Parameter Design}

\subsection{Circuit Characteristic}

The s-transfer function for Matrixes (7) and (8) are deduced from the 4B- $L C L$ complex vector model in the non-zero-sequence and zero-sequence in Figure 6. Because the zero-sequence grid voltage equals approximately zero in practical situations, the zero-sequence concerned is not included in Matrix (8).

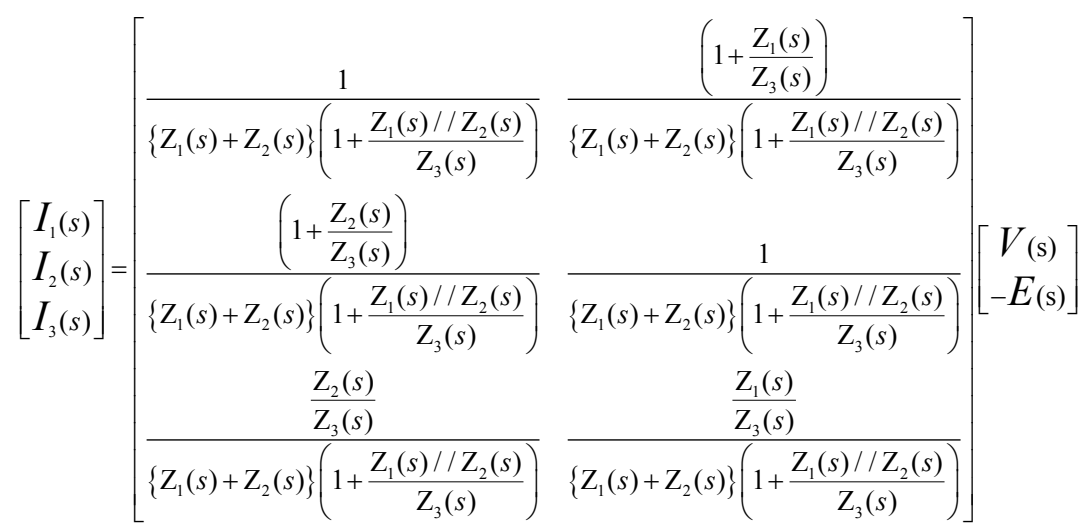




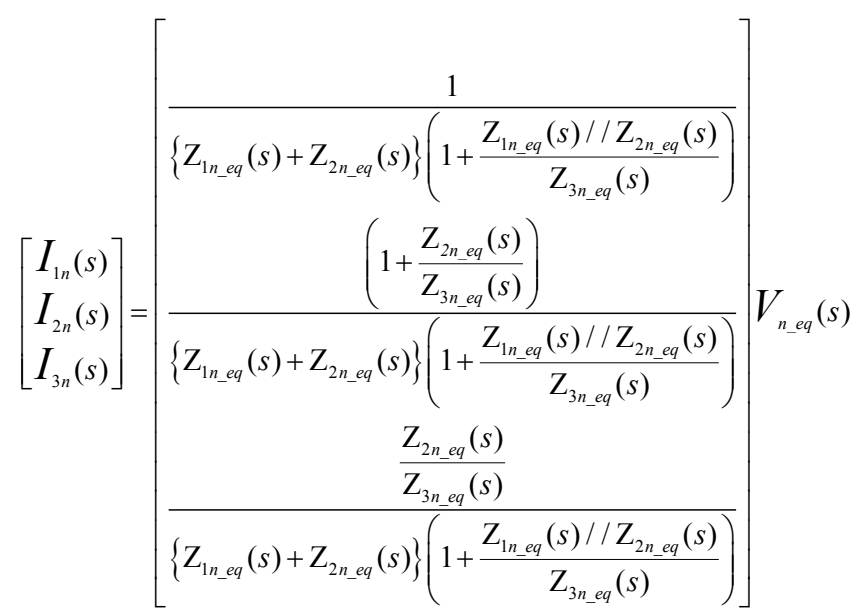

where

$$
Z_{1}(s)=L_{1} s+R_{1}, Z_{2}(s)=L_{2} s+R_{2}, Z_{3}(s)=1 / C s+R
$$

Because the s-transfer functions in Matrixes (7) and (8) have a unified form, only the former one has been considered in the circuit characteristic analysis. The bode plots shown in Figure 7 are obtained from Matrix (7), in which $L_{1}=0.23 \mathrm{mH}, L_{2}=0.03 \mathrm{mH}, C=30 \mu \mathrm{F}$, and $R=0.1 \Omega$. The two amplitude-frequency curves have the same shape, sharing characteristics of three stages: an initial decrease, followed by an increase and sharp decrease, and finally a continuous decrease.
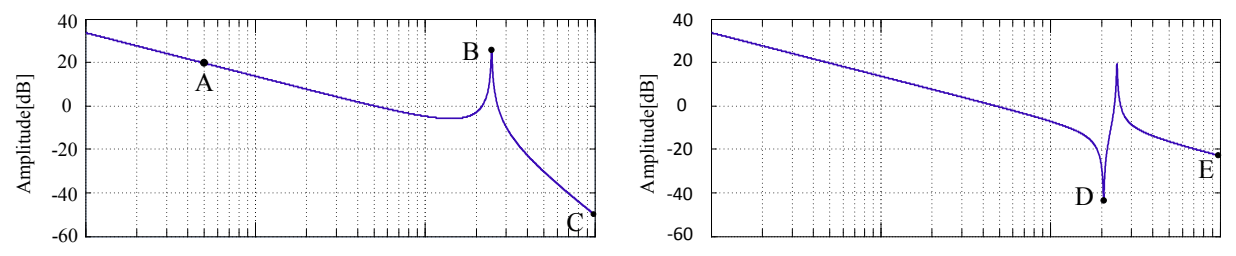

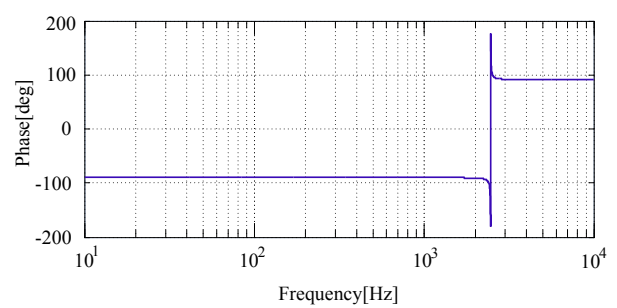

(a)

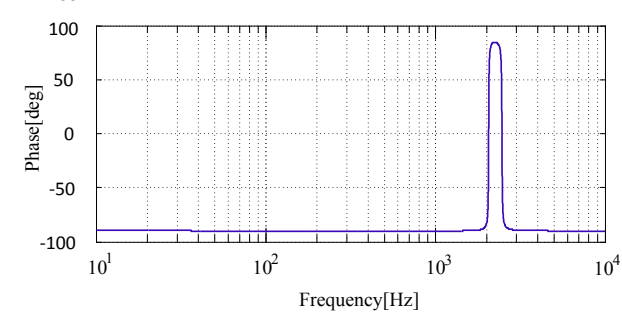

(b)

Figure 7. Bode diagrams (a) $I_{2}(s) / V(s)$, (b) $I_{l}(s) / V(s)$.

Five points will be illustrated in detail as follows; whose values alone fully indicate the performance of the designed LCL circuit. In Figure 7a, point A is in the fundamental frequency corresponding position. Point $\mathrm{B}$ is in the peak position. Point $\mathrm{C}$ is in the switching frequency position. In Figure $7 \mathrm{~b}$, Point $\mathrm{D}$ is in the lowest position of the curve. Point $\mathrm{E}$ is in the switching frequency position. Two events have occurred in Points B and D, which are the so-called series resonance and parallel resonance. To combine the qualitative and quantitative analyses, four types of impedance s-transfer functions are introduced for further analysis in Equations in (9)-(11). 


$$
\begin{array}{r}
G_{11}(s)=\frac{\left\{Z_{1}(s)+Z_{2}(s)\right\}\left(1+\frac{Z_{1}(s) / / Z_{2}(s)}{Z_{3}(s)}\right)}{\left(1+\frac{Z_{2}(s)}{Z_{3}(s)}\right)} \\
G_{22}(s)=\frac{\left\{Z_{1}(s)+Z_{2}(s)\right\}\left(1+\frac{Z_{1}(s) / / Z_{2}(s)}{Z_{3}(s)}\right)}{\left(1+\frac{Z_{1}(s)}{Z_{3}(s)}\right)} \\
G_{12}(s)=G_{21}(s)=\left\{Z_{1}(s)+Z_{2}(s)\right\}\left(1+\frac{Z_{1}(s) / / Z_{2}(s)}{Z_{3}(s)}\right)
\end{array}
$$

$G_{11}$ is the impedance between the PWM voltage and converter-side current, referred to as the converter-side impedance. $G_{22}$ is the impedance between the grid-voltage and grid-side current, named grid-side impedance. $G_{12}$ is the impedance between the PWM voltage and grid-side current. $G_{21}$ is the impedance between the grid-voltage and converter-side current. Because of the symmetry of the $L C L$ circuit, the impedance $G_{21}$ equals $G_{12}$. Thus, $G_{21}$ and $G_{12}$ are both named the dual-side impedance.

In the proposed impedance perspective, the most comprehensive performance indexes from the designed $L C L$ circuit parameters $\left(L_{1}, L_{2}, C\right.$, and $\left.R\right)$ are described in detail below:

(1) Dual-side impedance amplitude within the output current frequency band:

$$
P_{1}=\left|G_{12}\right|_{s=\mathrm{j} n \omega_{1}} \approx\left|\left\{Z_{1}(s)+Z_{2}(s)\right\}\right|_{s=\mathrm{j} n \omega_{1}} \approx\left(L_{1}+L_{2}\right) n \omega_{1} \quad(n=1,2,3 \ldots N)
$$

This index in (12) (where $\mathrm{N}$ is the highest order of the output current frequency) indicates the capacity of an APF with a finite DC voltage and a certain grid voltage at the aspect of the output current's di/dt, which is referred to as the APF output capacity [12]. A lower impedance amplitude value indicates a higher APF output capacity, and vice versa. In the frequency domain, lower impedance amplitude means higher capacity in outputting high-order frequency current in some other conditions [19]. Because the impedance amplitude is proportional to its frequency within the output current frequency band, the dual-side impedance amplitude in the fundamental frequency is selected for this performance index in practical use, which is $\left(L_{1}+L_{2}\right) \omega_{1}$. A certain APF output capacity requirement corresponds to its upper limit value.

(2) Dual-side impedance amplitude in the switching frequency:

$$
P_{2}=\left|G_{12}\right|_{s=\mathrm{j} \omega_{s}} \approx\left|\left\{Z_{1}(s) Z_{2}(s) / Z_{3}(s)\right\}\right|_{s=\mathrm{j} \omega_{s}} \approx L_{1} L_{2} C \omega_{s}^{3}
$$

This index indicates the content of the grid-side current ripple produced by a certain PWM voltage. A smaller grid-side current ripple results in a better performance of the designed LCL [25]. Thus, this principal and critical index should be kept larger than a lower limit.

(3) Converter-side impedance amplitude in the switching frequency:

$$
P_{3}=\left|G_{11}\right|_{s=\mathrm{j} \omega_{s}} \approx\left|\mathrm{Z}_{1}(s)\right|_{s=\mathrm{j} \omega_{s}} \approx L_{1} \omega_{s}
$$

This index indicates the content of the converter-side current ripple produced by a certain PWM voltage. Although the converter-side current ripple will be mostly filtered out from injecting into the grid by the filter-side $R C$-plant (as shown in Figure 8), it is related to some practical considerations: 
the maximum current of the semiconductor switching devices, the saturation characteristic of the inverter-side inductance, the EMI of the APF, and so on [25]. Thus, this index should be kept larger than a lower limit as well.

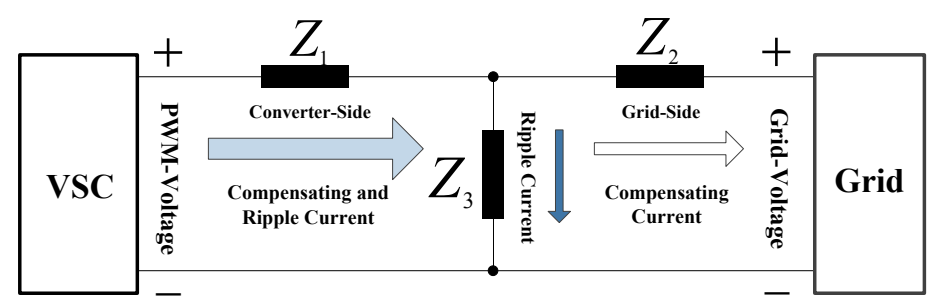

Figure 8. Diagram of the current flow path in the LCL circuit.

(4) Series resonant frequency:

$$
\omega_{\text {res }}=\sqrt{\frac{1}{L_{p} C}}
$$

where $L_{p}=L_{1} L_{2} /\left(L_{1}+L_{2}\right)$

The index indicates the same series resonant event in both sides of the $L C L$ circuit, which can be considered as the frequency in which the numerator term $Z_{p}(\mathrm{~s})+Z_{3}(\mathrm{~s})$ in Equations (9)-(11) becomes a real resistor impendence. The index should be selected between the output current upper-limit frequency and half of the controller sampling frequency, which is half of or equal to the switching frequency. In [9], the recommended value is $2 \omega_{n}<\omega_{\text {res }}<0.5 \omega_{s}$.

(5) Parallel resonant frequency:

$$
\begin{aligned}
& \omega_{01}=\sqrt{\frac{1}{L_{2} C}} \\
& \omega_{02}=\sqrt{\frac{1}{L_{1} C}}
\end{aligned}
$$

The indexes in Equations (16) and (17) indicate the two parallel resonant events on the converter side and grid side of the $L C L$ circuit, which can be considered as the frequency where the denominator terms $Z_{2}(\mathrm{~s})+Z_{3}(\mathrm{~s})$ and $Z_{1}(\mathrm{~s})+Z_{3}(\mathrm{~s})$ in Equations (9)-(10) become a real resistor impendence. Because the direct grid-side current control is adopted commonly, only the index in Equation (17) needs to be considered. A lower index indicates that the high-order background harmonics of the grid voltage have a greater influence over the current controller [19]. Thus, the index should be kept larger than a lower limit value.

(6) Filter-side impedance amplitude in the fundamental frequency:

$$
P_{4}=\left|Z_{3}(s)\right|_{s=\mathrm{j} \omega_{1}} \approx \frac{1}{C \omega_{1}}
$$

This index indicates the content of the main fundamental frequency component in the filter-side current produced by the grid voltage, which also mainly consists of the fundamental frequency 
component. A higher impedance amplitude leads to a lower filter-side current. Thus, this index should be restricted to limit the power loss in the filter-side branch.

(7) Dual-side impedance amplitude in the series resonant frequency:

$$
P_{5}=\left|G_{12}\right|_{s=\mathrm{j} \omega_{\text {res }}} \approx\left(L_{1}+L_{2}\right) C R \omega_{\text {res }}^{2}=R /(1-\alpha) / \alpha
$$

where $\alpha=L_{1} /\left(L_{1}+L_{2}\right)$

This index indicates the damping effect of the designed $L C L$ circuit directly. A higher impedance amplitude results in a lower peak value of the amplitude-frequency curve in the Bode plots and thus a stronger damping effect. The index is determined by the series resistance $R$ if the total inductance and the capacitance $\mathrm{C}$ have been determined. In [25], the recommended value is $R<1 / 3 / C / \omega_{\text {res }}$.

\subsection{Design Procedure}

The most comprehensive performance indexes have been obtained above. The essential aspect of the $L C L$ parameter design is to meet the performance requirements. Generally, a good performance index will inevitably increase the cost, size, and weight of the $L C L$ components $\left(L_{1}, L_{2}, C\right.$ or $\left.R\right)$. Hence, a compromise should be made to keep a balance between performance and cost, size, and weight.

The algorithm for designing the $L C L$ circuit is shown in Figure 9. It contains three tasks: determining the performance index, meeting the performance requirement and verifying the performance index.

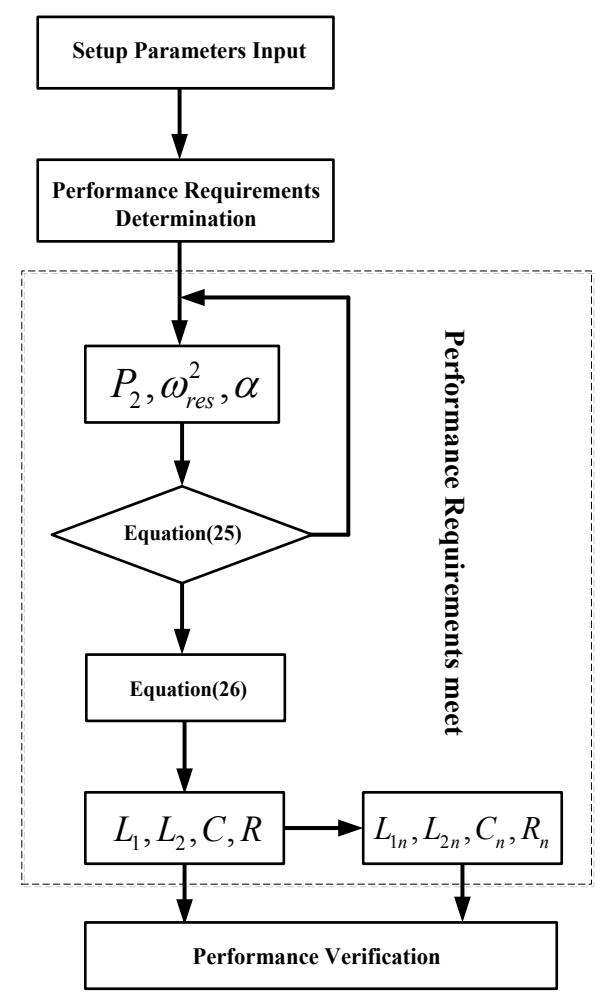

Figure 9. Flowchart of the $L C L$ design.

3.2.1. Determination of the Performance Requirements

(1) Calculate the maximum limitation of $P_{1}$ which is determined by the total inductance $L=L_{1}+L_{2}$. To ensure the rated current output capacity of the APF, the following inequality should be satisfied: 


$$
I_{r m s} P_{1} \leq m V_{d c}-n E_{r m s}
$$

where $I_{r m s}$ is the rated output current of the APF, $E_{r m s}$ is the rms of the grid rated line voltage, $n$ is the ratio of voltage fluctuation (generally $5 \%-10 \%), V_{d c}$ is the DC-side voltage, and $m$ is the ratio of DC voltage utilization, which is determined by the adopted PWM strategy (e.g., $1 / 2 / \sqrt{2}$ if the per-phase PWM strategy is adopted, $1 / \sqrt{3} / \sqrt{2}$ if the space vector PWM strategy is adopted).

(2) Estimate the maximum value of the PWM voltage ripple in the switching frequency denoted by $V_{r}$ and further calculate the limitations of $\mathrm{P}_{2}$ and $\mathrm{P}_{3}$ according to Equation (21). The maximum values of the converter-side and grid-side current ripple in the switching frequency are denoted by $I_{r 1}$ and $I_{r 2}$. There are various harmonic components in the PWM voltage. The high-frequency harmonic components, which are determined by the type of modulation, DC link voltage, and waveform of the PWM reference voltage (e.g., modulation index), appear on switching and its multiple frequencies, and the uppermost component is around the switching frequency [9]. $V_{r}$ can also be obtained from the simulation of a practical situation.

$$
\left\{\begin{array}{l}
V_{r} / P_{3} \leq I_{r 1} \\
V_{r} / P_{2} \leq I_{r 2}
\end{array}\right.
$$

(3) Determine the range of the series and parallel resonant frequency, which is shown in Equation (22). $\omega_{g h}$ is the highest frequency of the grid background harmonics voltage.

$$
\left\{\begin{array}{l}
2 \omega_{n}<\omega_{r e s}<0.5 \omega_{s} \\
2 \omega_{g h}<\omega_{02}
\end{array}\right.
$$

(4) Determine the range of the $R$ and $C$ in the filter-side branch according to P4 and P5. $I_{c l}$ is the maximum fundamental frequency current in the filter-side branch, which is caused by the grid. P5 should be above one for the close-loop control stability [12]. Thus, the range of $\mathrm{R}$ is obtained via Equation (24).

$$
\begin{gathered}
E_{1} / P_{4}<I_{c 1} \\
\alpha(1-\alpha)<R<\frac{1}{3 C \omega_{r e s}}
\end{gathered}
$$

\subsubsection{Meeting the Performance Requirements}

The inequality in Equation (25) can be obtained based on Equations (20)-(24). According to the flowchart of the $L C L$ design in Figure 9, the $L C L$ parameters can be determined by a simple trial-and-error process. The essential aspect of the process is utilizing the performance indexes $P_{2}$, $\omega_{\text {res }}$ and $\alpha$ to deduce the proper $L_{l}, L 2, C, R$ that can meet the inequality in Equation (25) and reach the optimal target, which is to maximize $P_{2} / L$. 


$$
\begin{aligned}
& \left\{\begin{array}{l}
P_{2} \geq P_{2 \min } \\
\frac{1}{4 \omega_{n}^{2}} \geq \omega_{r e s}^{2} \geq \frac{4}{\omega_{s}^{2}} \\
1>\alpha \geq 0.5 \\
P_{1}=\omega_{r e s}^{2} P_{2}\left(\frac{\omega_{1}}{\omega_{s}^{3}}\right) \leq P_{1 \max } \\
P_{3}=\omega_{r e s}^{2} P_{2} \alpha\left(\frac{1}{\omega_{s}^{3}}\right) \geq P_{3 \min } \\
P_{4}=\alpha(1-\alpha) \omega_{r e s}^{4} P_{2}\left(\frac{1}{\omega_{s}^{3} \omega_{1}}\right) \geq P_{4 \min } \\
\omega_{01}^{2}=\omega_{r e s}^{2}(1-\alpha) \geq 4 \omega_{g h}^{2}
\end{array}\right. \\
& \left\{\begin{array}{l}
L_{1}=\omega_{r e s}^{2} P_{2} \alpha\left(\frac{1}{\omega_{s}^{3}}\right) \\
L_{2}=\omega_{r e s}^{2} P_{2}(1-\alpha)\left(\frac{1}{\omega_{s}^{3}}\right) \\
C=\frac{\omega_{s}^{3}}{\alpha(1-\alpha) \omega_{r e s}^{4} P_{2}} \\
\frac{1}{3 C \omega_{r e s}}>R>\alpha(1-\alpha)
\end{array}\right.
\end{aligned}
$$

3.2.3. Verification of the Performance Index

The $L C L$ performance index output table should be contained in an integral $L C L$ design procedure for the design specification. Additionally, the selected parameters in a practical situation may differ from the calculated ones. Thus, a practical performance index output table is necessary.

\section{Simulation}

The simulation model is established in MATLAB/Simulink. The purpose of the simulation is to verify the current ripple filtering effect of the designed $4 B-L C L$; therefore, it is carried out by the open-loop method excluding the APF's controller. The parameters of the designed $4 B-L C L$ are obtained by the method mentioned above. All simulation parameters are shown in Tables 1-4. 
Table 1. Setup parameters.

\begin{tabular}{ccc}
\hline Symbol & Quantity & Value \\
\hline$E_{r m s}$ & Phase grid voltage & $200-240 \mathrm{~V}$ \\
$f_{g h}$ & Highest background voltage harmonics frequency & $550 \mathrm{~Hz}$ \\
$h$ & Highest frequency order of the output current harmonics & 20 \\
$m$ & DC Voltage Utilization Ratio & $1 / \sqrt{3} / \sqrt{2}$ \\
$V_{d c}$ & DC Link Voltage & $800 \mathrm{~V}$ \\
$f_{s}$ & Switching Frequency & $10 \mathrm{KHz}$ \\
$I_{r m s}$ & Rated Output Current in phases A, B, C, and N & $100 \mathrm{~A}$ \\
$I_{r 1}$ & Converter-side current ripple rms in phases A, B, C, and N & $\leq 12 \mathrm{~A}$ \\
$I_{r 2}$ & Grid-side current ripple rms in phases A, B, C, and N & $\leq 1 \mathrm{~A}$ \\
\hline
\end{tabular}

Table 2. Table of performance requirements in phases A, B, C, and N.

\begin{tabular}{ccc}
\hline Symbol & Quantity & Value \\
\hline$P_{1}$ & Dual-side impedance amplitude in the fundamental frequency & $\leq 0.87 \Omega$ \\
$P_{2}$ & Dual-side impedance amplitude in the switching frequency & $\geq 295.2 \Omega$ \\
$P_{3}$ & Converter-side impedance amplitude in the switching frequency & $\geq 10.0 \Omega$ \\
$P_{4}$ & Filter-side impedance amplitude in the fundamental frequency & $\geq 40.0 \Omega$ \\
$P_{5}$ & Dual-side impedance amplitude in the series resonant frequency & approximately $1.0 \Omega$ \\
$f_{\text {res }}$ & Dual-side series resonant frequency & {$[2.0 \mathrm{KHz}, 5.0 \mathrm{KHz})$} \\
$f_{01}$ & Grid-side parallel resonant frequency & {$\left[1.1 \mathrm{KHz}, f_{\text {res }}\right)$} \\
\hline
\end{tabular}

Table 3. Parameters selected and its performance index in phases A, B, and C.

\begin{tabular}{|c|c|c|}
\hline Symbol & Quantity & $\begin{array}{l}\text { Value: the selected } \\
\text { (the calculated) }\end{array}$ \\
\hline$L_{1}$ & Converter-side inductance & $0.23 \mathrm{mH}(0.273 \mathrm{mH})$ \\
\hline$L_{2}$ & Grid-side inductance & $0.10 \mathrm{mH}(0.086 \mathrm{mH})$ \\
\hline$C$ & Filter-side capacitance & $60 \mu \mathrm{F}(56.92 \mu \mathrm{F})$ \\
\hline$R$ & Filter-side resistance & $0.2 \Omega(0.196 \Omega)$ \\
\hline$P_{1}$ & \multirow{7}{*}{$\begin{array}{l}\text { Performance Index Output } \\
\text { in phases } \mathrm{A}, \mathrm{B} \text {, and } \mathrm{C}\end{array}$} & $0.1 \Omega$ \\
\hline$P_{2}$ & & $301.0 \Omega$ \\
\hline$P_{3}$ & & $14.2 \Omega$ \\
\hline$P_{4}$ & & $53.1 \Omega$ \\
\hline$P_{5}$ & & $0.93 \Omega$ \\
\hline$f_{\text {res }}$ & & $2.46 \mathrm{KHz}$ \\
\hline$f_{01}$ & & $2.05 \mathrm{KHz}$ \\
\hline
\end{tabular}


Table 4. Parameters selected and its performance index in phase N.

\begin{tabular}{|c|c|c|}
\hline Symbol & Quantity & $\begin{array}{l}\text { Value: the selected } \\
\text { (the calculated) }\end{array}$ \\
\hline$L_{1 \mathrm{n}}$ & Converter-side inductance & $0.32 \mathrm{mH}(0.312 \mathrm{mH})$ \\
\hline$L_{2 \mathrm{n}}$ & Grid-side inductance & $0.14 \mathrm{mH}(0.138 \mathrm{mH})$ \\
\hline$C_{n}$ & Filter-side capacitance & $42 \mu \mathrm{F}(41.74 \mu \mathrm{F})$ \\
\hline$R_{n}$ & Filter-side resistance & $0.15 \Omega(0.145 \Omega)$ \\
\hline$L_{1 \mathrm{n} \mathrm{eq}}$ & \multirow{4}{*}{$\begin{array}{l}\text { Equivalent Value } \\
\text { in phase } \mathrm{N}\end{array}$} & $0.40 \mathrm{mH}$ \\
\hline$L_{2 \mathrm{n} \_\mathrm{eq}}$ & & $0.16 \mathrm{mH}$ \\
\hline$C_{\mathrm{n} \text { eq }}$ & & $33.53 \mu \mathrm{F}$ \\
\hline$R_{\mathrm{n} \_ \text {eq }}$ & & $0.21 \Omega$ \\
\hline$P_{1 \mathrm{n}}$ & \multirow{7}{*}{$\begin{array}{l}\text { Performance Index Output } \\
\text { in phase } \mathrm{N}\end{array}$} & $0.028 \Omega$ \\
\hline$P_{2 \mathrm{n}}$ & & $559.4 \Omega$ \\
\hline$P_{3 \mathrm{n}}$ & & $19.2 \Omega$ \\
\hline$P_{4 \mathrm{n}}$ & & $94.88 \Omega$ \\
\hline$P_{5 \mathrm{n}}$ & & $1.23 \Omega$ \\
\hline$f_{\text {res_n }}$ & & $2.53 \mathrm{KHz}$ \\
\hline$f_{01 n}$ & & $2.21 \mathrm{KHz}$ \\
\hline
\end{tabular}

\subsection{Current Ripple Filtering in Different PWM Voltage Modulation Indexes}

Table 5 illustrates that the magnitude of the switching frequency output voltage ripples is inversely proportional to the modulation index. With the increase of the modulation index, the grid-side current ripple of the switching frequency was reduced steadily. When the index is 1.0, by installing the proposed 4B-LCL interface, the switching frequency ripple currents in phases $\mathrm{A}$ and $\mathrm{N}$ have been reduced from 12.13 A and 20.65 A to 0.21 A and 0.84 A, respectively, which has provided great filtering results.

Table 5. Results of the current ripple filtering in different PWM voltage modulation indexes.

\begin{tabular}{ccccccc}
\hline & \multicolumn{2}{c}{ PWM Voltage } & & \multicolumn{2}{c}{ Switching frequency current rms/A } & \multicolumn{2}{c}{$\begin{array}{c}\text { Damping resister } \\
\text { Modulation index }\end{array}$} & Switching frequency voltage & & Converter-side (A,N) & Grid-side (A,N) & power loss (w) \\
\cline { 1 - 2 } 0.0 & $357.93,600.93$ & & $90.04,120.33$ & $4.09,6.04$ & $1632 \mathrm{~W}$ \\
0.2 & $300.12,463.46$ & & $60.02,98.12$ & $3.09,5.83$ & $800 \mathrm{~W}$ \\
0.4 & $260.34,300.62$ & & $50.17,70.58$ & $2.09,3.92$ & $300 \mathrm{~W}$ \\
0.6 & $190.83,263.91$ & & $30.18,50.11$ & $1.09,1.93$ & $93 \mathrm{~W}$ \\
1.0 & $90.34,220.46$ & & $12.13,20.65$ & $0.21,1.19$ & $21 \mathrm{~W}$ \\
\hline
\end{tabular}

Figure 10 shows the simulation waveforms indicating the ripple current filtering effect by the designed $4 B-L C L$ interface. 

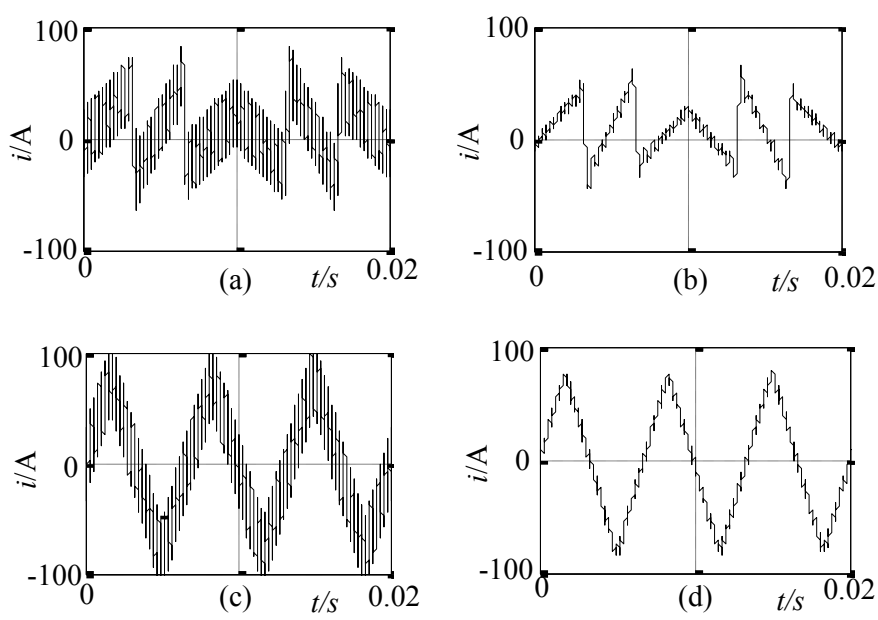

Figure 10. Comparison between converter-side and grid-side current in phases $A$ and $N$. (a) and (c) show the current waveforms in the converter side in phases A and N. (b) and (d) show the current waveforms in the grid side in phases A and N. The figure clearly shows the filtering effect by the proposed 4B-LCL interface. The grid-side current waveform is considerably smoother than that of the converter side.

\subsection{Current Ripple Filtering by the LCL Branch in Phase N}

Figure 11 shows the grid-side current waveforms of phase $\mathrm{N}$ at the $R C$-plant switching time. It can be seen that $i_{s a}$ and $i_{s n}$ have many high frequency current ripples before the $R C$-plant in n-phase has been switched on, but the high frequency current ripples have almost disappeared after it has been switched on. In particular, the current ripple in $i_{s n}$ has been decreased from $10 \mathrm{~A}-0.9 \mathrm{~A}$. This result verifies the good effect on current ripple filtering of the $L C L$-branch in phase $\mathrm{N}$.

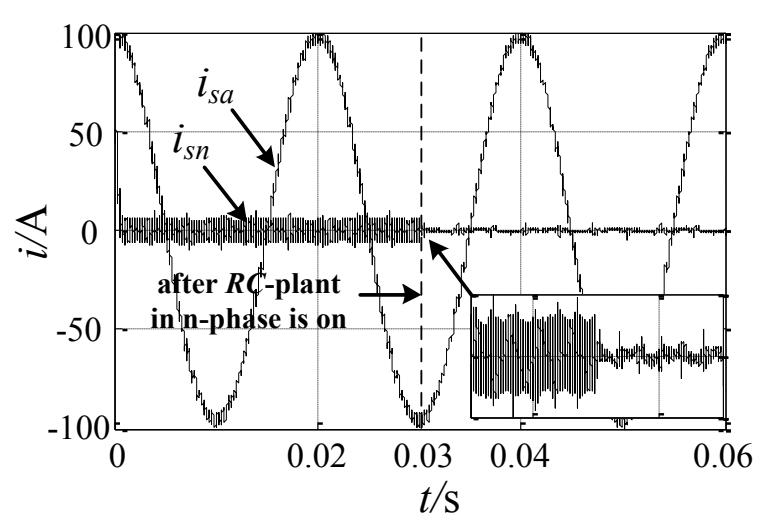

Figure 11. Comparison with and without the $L C L$ branch in phase N.

\section{Experimental Results}

\subsection{Experimental Platform}

Figure 12a shows the experimental platform, where SKM400GB176D from SEMIKRON was selected as the power module IGBT, and TMS320F28335 from Texas Instruments was selected as 
the main controller chip for digital signal processing. In addition, the platform has adopted the power quality analyzer (Fluke 434B) and Oscilloscope (Tektronix 2024B) as measurement instruments in Figure 12b,c. The actual $4 B-L C L$ circuit implemented is shown in Figure 13.

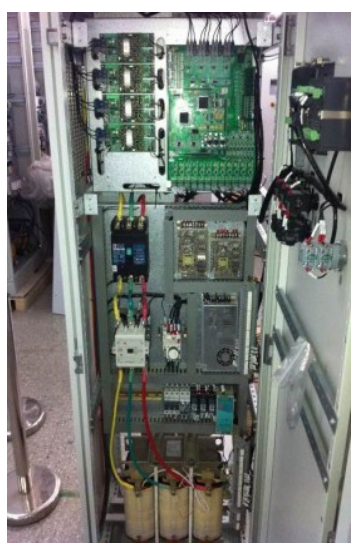

(a)

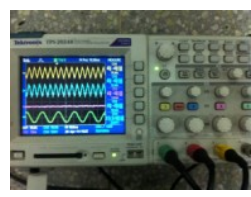

(b)

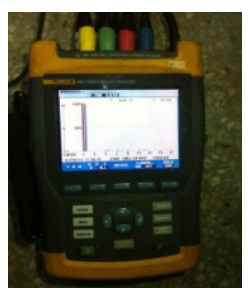

(c)

Figure 12. Experimental platform and measurement instruments.

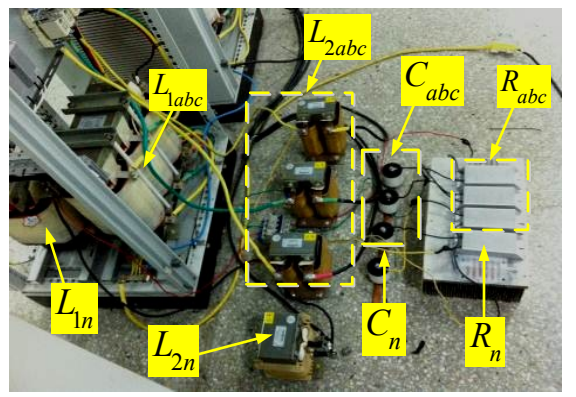

Figure 13. Implemented $4 B-L C L$ circuit.

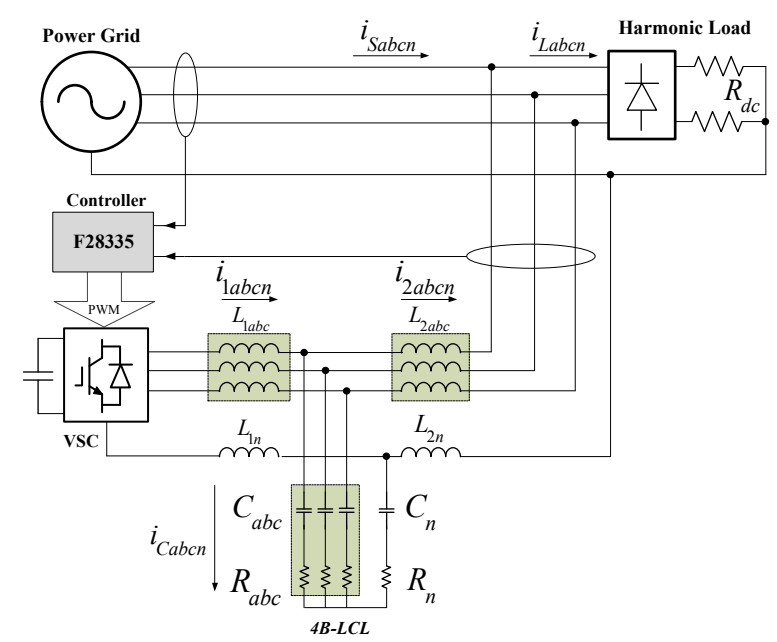

Figure 14. Experimental system.

The experimental system consists of the controller, voltage source converter (VSC), harmonic load, three-phase four-wire power grid, and proposed four-branch (4B) $L C L$ grid-connecting interface, as shown in Figure 14. The APF controller sampled the grid-side current to directly regulate the output current, 
which is injected into the grid to fully compensate for the load current harmonics. The harmonic load was modified from the typical three-phase uncontrolled rectifier bridge, where the midpoint of the resistors on the DC side was connected to phase $\mathrm{N}$ of the power grid for the purpose of getting the current harmonics in this phase. In addition, the parameters of the experiment are the same as in the simulation above.

\subsection{Experimental Results}

\subsubsection{Current Ripple Filtering}

Figure $15 \mathrm{a}, \mathrm{b}$ show the current waveforms of the proposed $4 B-L C L$ in phase A and N, when the APF is fully compensating the load current harmonics. In this figure, $I_{1 a} \& I_{1 n}, I_{C a} \& I_{C n}, I_{2 a} \& I_{2 n}$, and $E_{a n}$ are the converter-side current, filter-side current, grid-side current, and grid voltage, respectively, between phases $\mathrm{A}$ and $\mathrm{N}$. Because the three phases are symmetric, it is not necessary to demonstrate the waveforms in phases $\mathrm{B}$ and $\mathrm{C}$. These waveforms illustrate that $I_{l a} \& I_{l n}$ have a massive high-frequency current ripple, which has been filtered out into $I_{c a} \& I_{c n}$. $I_{2 a} \& I_{2 n}$ have a smoother waveform than $I_{l a} \& I_{l n}$. Furthermore, Figure $15 \mathrm{c}$ is a zoomed-in view of the dashed box in Figure 15. The period of the high-frequency ripple wave in $I_{l n}$ and $I_{C n}$ is approximately $0.1 \mathrm{~ms}$ (which is just the switching period of IGBT), and their amplitudes are nearly identical. The current ripple of the grid-side current $I_{2 n}$ has been greatly reduced, and the waveform of the grid voltage $E_{a n}$ is also extremely smooth. Therefore, the designed $4 B-L C L$ has obtained a good performance in the current ripple filtering.

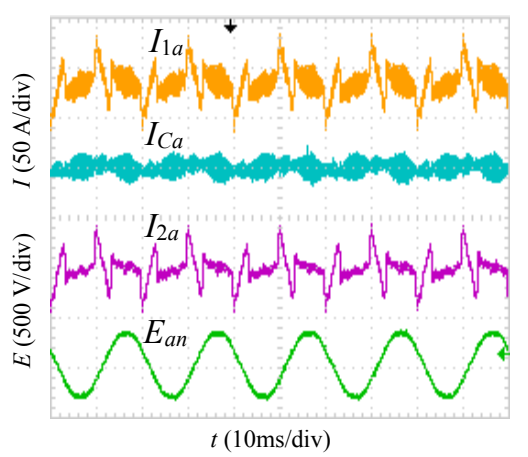

(a)

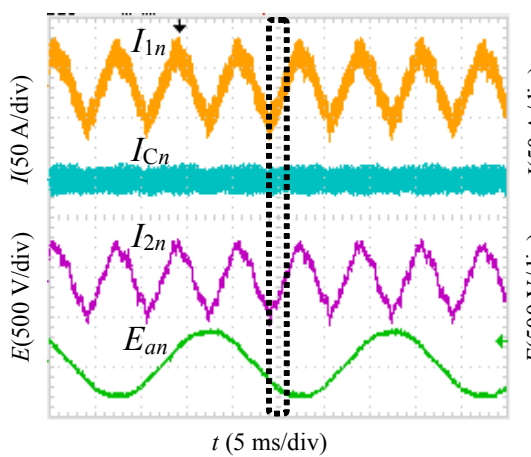

(b)

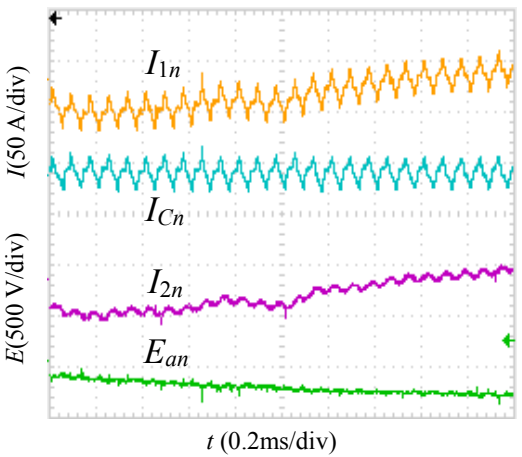

(c)

Figure 15. Waveforms of the $4 B-L C L$ (a) in phase $\mathrm{A}(\mathbf{b})$ in phase $\mathrm{N}(\mathbf{c})$ Zoomed-in view.

Figure 16a,b show the FFT results of the converter-side and grid-side current in phase N. A large amount of current ripples around the switching frequency are contained in the converter-side current. The ripple content reaches approximately $32 \mathrm{~dB}$ at the switching frequency $f_{s}$ and $3 f_{s}$, whereas that in the grid-side current has been evidently reduced to approximately $10 \mathrm{~dB}$ around $f_{s}$ and to a negligible level around other integral multiples of $f_{s}$. This experimental result has further verified the current ripple reduction effect in phase $\mathrm{N}$ of the designed $4 B-L C L$ circuit. 


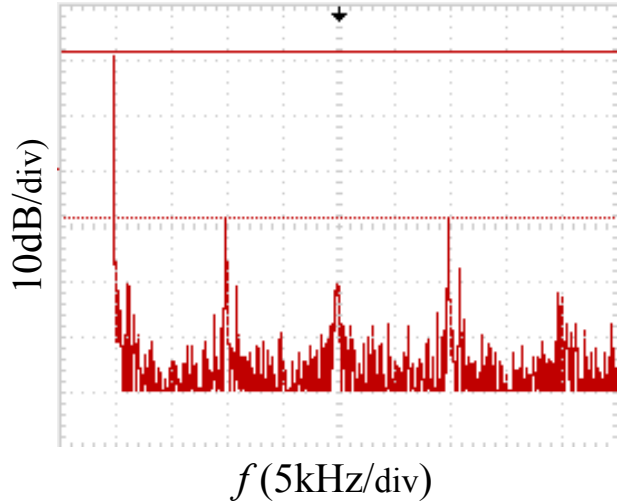

(a)

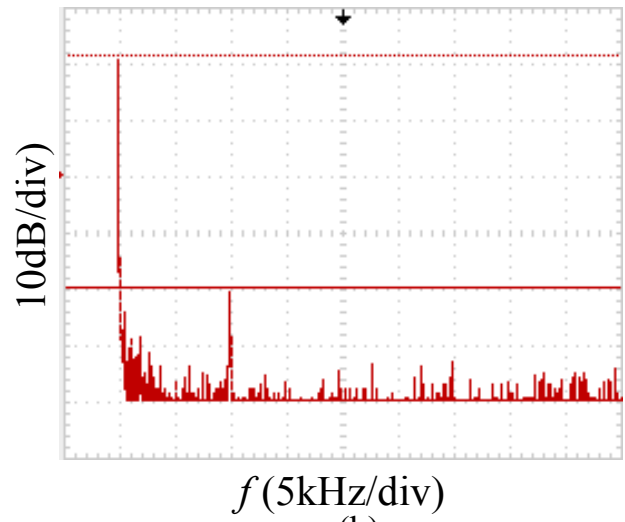

(b)

Figure 16. FFT of the current in phase N (a) converter-side (b) grid-side.

\subsubsection{Harmonic Compensation}

Figure $17 \mathrm{a}, \mathrm{b}$ are the current waveforms in phase A and $\mathrm{N}$ when the APF is fully compensating the load current harmonics. $I_{L a} \& I_{L n}, I_{2 a} \& I_{2 n}, I_{S a} \& I_{S n}$ are the load current, compensating current, and grid current, respectively, in phases A and N. $E_{a n}$ is the grid voltage between phases A and N. In Figure $17 \mathrm{a}$, the load current $I_{L a}$ is considerably distorted. However, the grid current $I_{S a}$ has a good sinusoidal waveform due to the compensating current $I_{2 a}$. In Figure $17 \mathrm{~b}$, the period of the load current $I_{L n}$ in phase $\mathrm{N}$ is approximately $7 \mathrm{~ms}$, which indicates the existence of a large amount of the third harmonic current. The compensating current $I_{2 n}$ from the APF almost equals the lode current $I_{L n}$ in both amplitude and phase. Thus, the grid current in phase $\mathrm{N}$ is approximately zero, which means that the current harmonics in phase $\mathrm{N}$ are well compensated.

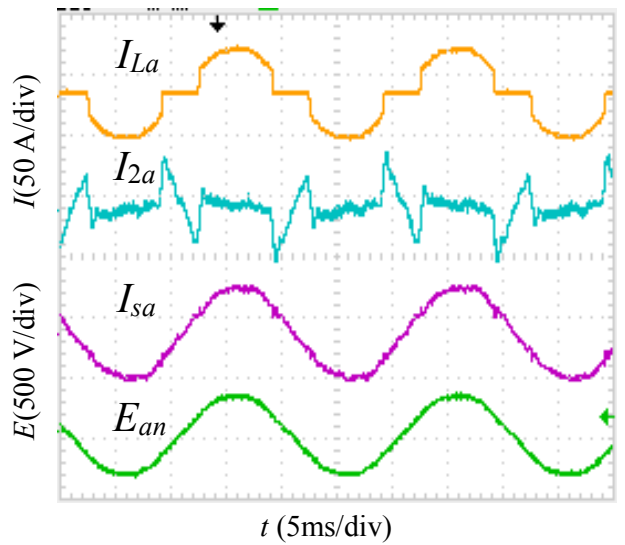

(a)

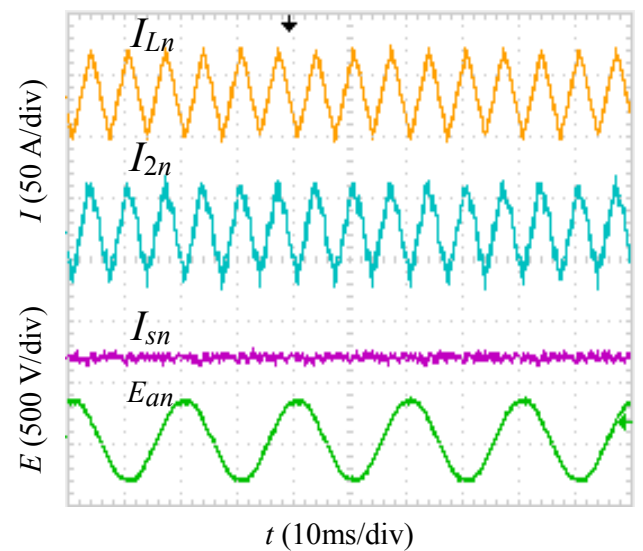

(b)

Figure 17. Waveforms in harmonic compensation (a) in phase A (b) in phase N.

Figure 18a,b shows the THD and ratio of harmonic frequency content in the load current and grid current. The current THD dropped from $23.7 \%, 23.8 \%$, and $23.9 \%$ in the load current to $4.0 \%, 4.1 \%$, and $4.1 \%$, respectively, in the grid current. The experimental result has met the requirement of THD in GB/T 14549-93. Each frequency harmonic distortion has dropped from over $1 \%$ in the load current to below $1 \%$ in the grid current. The good harmonic compensation result has further verified the effectiveness of the designed $4 \mathrm{~B}-L C L$ grid-connecting interface. 


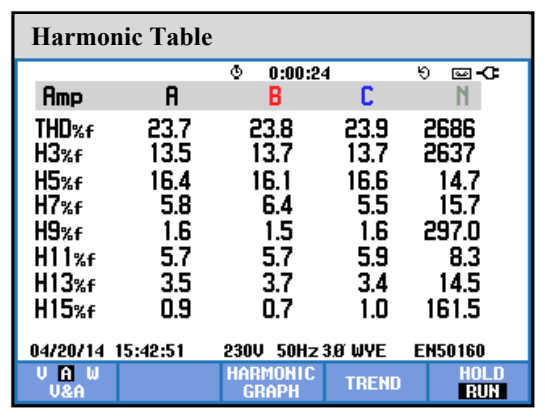

(a)

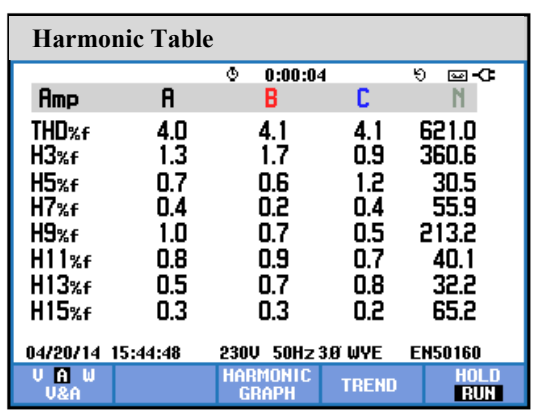

(b)

Figure 18. Harmonic forms of the (a) load current and (b) grid current.

\section{Conclusions}

Based on an analysis via mathematical models for decoupling and the most comprehensive performance indexes in the proposed impedance perspective, this paper has proposed a four-branch $L C L$-type grid-connecting interface and detailed parameter design procedure for a three-phase, four-leg active power filter. This paper focuses on two aspects: (1) describing the mathematical models of $4 B-L C L$ in the full complexity vector form from the zero and non-zero sequence perspectives, resulting in two independent and uniform equivalent circuits without cross-coupling terms; (2) proposing the $4 B-L C L$ parameter design method based on the most comprehensive performance index, including three main stages as the specification: performance requirements determination, fulfillment and verification. The Simulink results established in MATLAB and the experimental results obtained from the APF platform with the 4B-LCL type grid-connecting interface demonstrate that the 4B-LCL interface yields better current ripple filtering performance, which verifies the validity and effectiveness of the proposed design method.

\section{Acknowledgments}

This work is supported in part by grants from the National Natural Science foundation of China (Project No. 51477030), Innovation foundation for Combination of Industry and Scientific Research of Jiangsu Province, China (Project No. BY2014127-15).

\section{Author Contributions}

Wu Cao and Jianfeng Zhao designed the research; Wu Cao and Kangli Liu performed the research; $\mathrm{Wu}$ Cao, Yongchao Ji and Yigang Wang wrote the paper. All authors read and approved the final manuscript.

\section{Conflicts of Interest}

The authors declare no conflict of interest. 


\section{References}

1. Grino, R.; Cardoner, R.; Costa-Castello, R.; Fossas, E. Digital repetitive control of a three-phase four-wire shunt active filter. IEEE Trans. Ind. Electron. 2007, 54, 1495-1503.

2. Montero, M.; Cadaval, E.; Gonzalez, F. Comparison of control strategies for shunt active power filters in three-phase four-wires systems. IEEE Trans. Power Electron. 2007, 22, 229-236.

3. Le, J.; Jiang, Q.R.; Han, Y.D. The analysis of hysteresis current control strategy of three-phase four-wire APF based on the unified mathematic model. In Proceedings of the CSEE, Harbin, China, 23-25 May 2007; IEEE: Piscataway, NJ, USA, 2007; pp. 85-91.

4. Kanaan, H.Y.; Georges, S.; Mendalek, N.; Hayek, A.; Al-Haddad, K. A linear decoupling control for a PWM three-phase four-wire shunt active power filter. In Proceedings of the Electro Technical Conference, Ajaccio, France, 5-7 May 2008; IEEE: Piscataway, NJ, USA, 2008.

5. Petterson, S.; Salo, M.; Tuusa, H. Applying an LCL-filter to a four-wire active power filter. In Proceedings of the Power Electronics Specialists Conference, Jeju, Korea, 18-22 June 2006; IEEE: Piscataway, NJ, USA, 2006.

6. Khadkikar, V.; Chandra, A.; Singh, B. Digital signal processor implementation and performance evaluation of split capacitor, four-leg and three H-bridge-based three-phase four-wire shunt active filters. IET Power Electron. 2011, 4, 463-470.

7. Lin, J.Y.; Wang, Z.S.; Chen, H.M.; Li, C. High performance controller design for three-phase four-leg inverters. CSEE 2007, 27, 101-105.

8. Hirve, S.; Chatterjee, K.; Fernandes, B.G.; Imayavaramban, M.; Dwari, S. PLL-less active power filter based on one-cycle control for compensating unbalanced loads in three-phase four-wire system. IEEE Trans. Power Del. 2007, 22, 2457-2465.

9. Le, J.; Liu, K.P.; Tan, T.Y. A novel compound switching control strategy of the 4-leg shunt active power filter. CSEE 2011, 36, 62-70.

10. Guo, W.F.; Xu, D.G.; Wu, J.; Wang, L.G. Novel control method for $L C L$ active power filter. CSEE 2010, 30, 42-48.

11. Liu, F.; Zha, X.M.; Duan, S.X. Design and research on parameter of $L C L$ filter in three-phase grid-connected inverter. Trans. China Electr. Tech. Soc. 2010, 25, 110-116.

12. Liu, Q.; Peng, L.; Kang, Y.; Tang, S.Y.; Wu, D.L.; Qi, Y. A novel design and optimization method of an $L C L$ filter for a shunt active power filter. IEEE Trans. Ind. Electron. 2014, 61, 4000-4010.

13. Chen, Y.; Jin, X.M.; Tong, Y.B. Grid-side $L C L$-filter of three-phase voltage source PWM rectifier. Trans. China Electr. Tech. Soc. 2007, 22, 124-129.

14. Wang, Y.Q.; Wu, F.J.; Sun, L.; Sun, Q. Optimized design of $L C L$ filter for minimal damping power loss. CSEE 2010, 30, 90-95.

15. Ahmed, K.H.; Finney, S.J.; Williams, B.W. Passive filter design for three-phase inverter interfacing in distributed generation. In Proceedings of Compatibility in Power Electronics, Gdansk, Poland, 29 May-1 June 2007; IEEE: Piscataway, NJ, USA, 2007.

16. Wu, J.; Ma, X.; Hou, R.; Xu, D.G. Optimization of APF LCL output filter based on genetic algorithm. Trans. China Electr. Tech. Soc. 2011, 26, 159-164. 
17. Shri, A.; Popovic, J.; Ferreira, J.A.; Gerber, M.B. Design and control of a three-phase four-leg inverter for solid-state transformer applications. In Proceedings of Power Electronics and Applications, Lille, France, 2-6 September 2013; IEEE: Piscataway, NJ, USA, 2013.

18. Gabe, I.J.; Montagner, V.F.; Pinheiro, H. Design and implementation of a robust current controller for VSI connected to the grid through an LCL filter. IEEE Trans. Power Electron. 2009, 24, 1444-1452.

19. Reznik, A.; Simões, M.G.; Al-Durra, A.; Muyeen, S.M. $L C L$ filter design and performance analysis for grid-inter connected systems. IEEE Trans. Ind. Appl. 2014, 50, 1225-1232.

20. Wang, H.; Dou, Z.L.; Zhang, J.W.; Cai, X. Study on voltage sensor-less control for wind grid connection inverter with $L C L$ filter. Trans. China Electr. Tech. Soc. 2013, 28, 188-194.

21. Xu, J.M.; Xie, S.J.; Xiao, H.F. Research on control mechanism of active damping for $L C L$ filters. CSEE 2012, 32, 27-33.

22. Qiu, Z.L.; Yang, E.X.; Kong, J.; Chen, G.Z. Current loop control approach for $L C L$-based shunt active power filter. CSEE 2009, 29, 15-20.

23. Liserre, M.; Blaabjerg, F.; Hansen, S. Design and control of an LCL-filter-based three-phase active rectifier. In Proceedings of Industry Applications Conference, Chicago, IL, USA, 30 September-4 October 2001; IEEE: Piscataway, NJ, USA, 2005; pp. 1281-1291.

24. Pena, A.R.; Liserre, M.; Blaabjerg, F.; Sebastian, R.; Dannehl, J.; Fuchs, F.W. Analysis of the passive damping losses in LCL-filter-based grid converters. IEEE Trans. Power Electron. 2013, 28, 2642-2646.

25. Tang, Y.; Loh, P.C.; Wang, P.; Choo, F.H.; Gao, F.; Blaabjerg, F. Generalized design of high performance shunt active power filter with output $L C L$ filter. IEEE Trans. Ind. Electron. 2012, 59, 1443-1452.

(C) 2015 by the authors; licensee MDPI, Basel, Switzerland. This article is an open access article distributed under the terms and conditions of the Creative Commons Attribution license (http://creativecommons.org/licenses/by/4.0/). 